\title{
Hydrogen Transfer Steps in the Catalytic Hydrogenolysis of Cyclohexane
}

\author{
G. PARRAVANO \\ Department of Chemical and Metallurgical Engineering, The University \\ of Michigan, Ann Arbor, Michigan 48104
}

Received October 14, 1970

\begin{abstract}
The rate of the isotopic exchange reaction: cyclo- ${ }^{*} \mathrm{C}_{6} \mathrm{H}_{12}(\mathrm{~g})+\mathrm{C}_{\mathrm{g}}(\mathrm{g}) \rightarrow$ cyclo$\mathrm{C}_{n} \mathrm{H}_{12}(\mathrm{~g})+{ }^{*} \mathrm{C}_{\mathrm{e}}(\mathrm{g})(1)$ was studied over metal and metal oxide catalysts. $\mathrm{C}_{6}$ included: $n$-hexane, 2-methylpentane, 3-methylpentane, 2,2-dimethylbutane, and 2.3-dimethylbutane. The catalysts tested were: $\mathrm{Pt}$ supported on acidified and nonacidified $\mathrm{Al}_{2} \mathrm{O}_{3}$, $\mathrm{Cr}_{2} \mathrm{O}_{3}, \mathrm{Re}-\mathrm{Cr}_{2} \mathrm{O}_{3}, \mathrm{Cr}_{2} \mathrm{O}_{5}-\mathrm{Al}_{2} \mathrm{O}_{3}$ and $\mathrm{Re}-\mathrm{Al}_{2} \mathrm{O}_{3}$. The temperature range was 230 to $427^{\circ} \mathrm{C}$. The rate of reaction (1) was studied as a function of the ratio $p_{\mathrm{Co}} / p_{\mathrm{CHA}}$ in the range $3 \times 10^{-2}$ to $1 \times 10^{2}$. Since the reaction steps underlying reaction (1) include hydrogen transfer and rearrangement of the molecular structure, the experimental results have been analyzed in terms of these steps and information on their rate and thermodynamic and stoichiometric characteristics has been derived. The analysis suggested a mechanism for the transfer step that is influenced by catalyst acidity and hydrocarbon structure. Models for the reactive surface layer in metal and metal oxide catalysts are put forward and employed to indicate possibilities for the active sites at the surface. The models are also useful to interpret the observed phenomena of inversion in surface reactivity as a function of gas-phase composition. Finally, the experimental results and theoretical deductions are viewed in the framework of present information on the hydrogenolysis of cycloalkanes and isomerization of $\mathrm{C}_{\mathrm{a}}$ paraffins. The advantages of reaction (1) for fundamental studies on the hydroconversion of cycloalkanes are pointed out.
\end{abstract}

In previous work from this laboratory (1), a method for the study of the rate of the surface catalyzed hydrogen transfer between cyclohexane and benzene was investigated and applied to typical surfaces of $\mathrm{Pt}, \mathrm{Rh}, \mathrm{Ru}$, and $\mathrm{Pd}$. The method is based on experimental measurements of the rate of redistribution of a carbon isotope between benzene and cyclohexane. It permits the differentiation between the roles of thermodynamic and kinetic factors in the catalytic activity of surfaces and the study of the individual surface reaction steps, partaking in the overall catalytic change.

Because of the advantages of this method over traditional net reaction $\mathrm{ki}$ netics it was felt interesting to expand the investigations to cover hydrogen transfer steps which are accompanied by a rear- rangement of the molecular backbone. Knowledge of whether and, if so, of how much the general picture of the catalytic hydrogen transfer is modified whenever it includes a modification of the molecular configuration should eventually provide a rational framework for the discussion of skeletal rearrangements at catalytic surfaces and for the differentiation of these effects from those of the hydrogen transfer. The combination of hydrogen transfer and molecular rearrangement appears prominently in a variety of hydrocarbon conversion reactions. Thus, it was hoped that the proposed studies would add fresh interest to the knowledge gathered from classical investigations on the catalytic hydroconversion of hydrocarbons (2).

In this work, we chose to investigate the 
catalytic conversion of cyclohexane (CHA) to $\mathrm{C}_{6}$ alkanes: $n$-hexane (HA), 2-methylpentane (2-MPA), 3-methylpentane (3MPA), 2,2-dimethylbutane (2,2-DMBA) and 2,3-dimethylbutane (2,3-DMBA). The study was accomplished by measuring the rate of the reaction:

${ }^{*} \mathrm{CHA}(\mathrm{g})+\mathrm{C}_{6}(\mathrm{~g}) \rightarrow \mathrm{CHA}(\mathrm{g})+\mathrm{C}_{6}(\mathrm{~g})$,

where $\mathrm{C}_{6}$ and $(\mathrm{g})$ represent an hexane isomer and gas phase, respectively. The asterisk indicates a C-14 atom. At the reaction temperatures employed in this work $\left(300-400^{\circ} \mathrm{C}\right)$, only adsorption and desorption steps are considered kinetically significant, and consequently, reaction (1) may be viewed as the result of two surface steps of equal rates, viz.,

$$
\begin{aligned}
& { }^{*} \mathrm{CHA}(\mathrm{g})+2 \mathrm{H}(\mathrm{s}) \rightarrow{ }^{*} \mathrm{C}_{6}(\mathrm{~g}), \\
& \mathrm{C}_{6}(\mathrm{~g}) \rightarrow \mathrm{CHA}(\mathrm{g})+2 \mathrm{H}(\mathrm{s}),
\end{aligned}
$$

where (s) represents a catalyst surface. Since reaction step ( $1 b)$ is the reverse of reaction stcp (1a), their rates are similar (neglecting kinetic isotope effects) to the rate of reaction (1). As a consequence, experimental measurements on the rate of reaction (1) give directly the rate of the individual transfer steps (1a) and (1b). Because of the increased complexity of surface reaction steps (1a) and (1b) over the corresponding steps in the benzenecyclohexane conversion, it was expected that lower rate constants would be found in the present case as compared with those obtained in the hydrogen transfer between benzene and cyclohexane. In fact, for the latter case on $\mathrm{Pt}-\mathrm{Al}_{2} \mathrm{O}_{3}$ catalysts the rate constants were

$$
\sim 2.5 \times 10^{-7}\left[\frac{\mathrm{moles}}{\mathrm{g} \cdot \mathrm{sec} \cdot \mathrm{atm}}\right]
$$

at $117^{\circ} \mathrm{C}$ while for hydrogen transfer accompanied by ring fission ( $\mathrm{CHA} \rightarrow \mathrm{HA}$ ) as revealed in the present investigation, the rate constants on similar catalysts were found at $375^{\circ} \mathrm{C}$ to be one order of magnitude smaller than the value for the benzene $\rightarrow$ CHA conversion.

\section{EXPERIMENTAL}

\section{Materials}

Acidified and nonacidified Pt $(0.4$ wt \%) $\mathrm{Al}_{2} \mathrm{O}_{3}$ (1/16 in. spheres) and $\mathrm{Pt}(0.5$ wt $\%)-$ $\mathrm{SiO}_{2}$ were commercial preparations while Pt (1 wt \%) $-\mathrm{C}$ was supported on graphon particles. Chromia xerogel, from a sample prepared from urea and chromium nitrate (3), had a size between 80 to 100 meshes. $\operatorname{Re}\left(4.5\right.$ wt \%) - $\mathrm{Cr}_{2} \mathrm{O}_{3}$ was prepared by impregnation of chromia xerogel with a slightly acidified solution of $\mathrm{ReCl}_{3}$ and the paste was dried under ir lamp. Re $(6$ wt \%) $\mathrm{Al}_{2} \mathrm{O}_{3}$ was obtained by impregnation of $\mathrm{Al}_{2} \mathrm{O}_{3}$ (5/64 in. beads) with the $\mathrm{ReCl}_{3}$ solution. It was dried under ir lamp and heated at $360^{\circ} \mathrm{C}, 0.2$ Torr for $2 \mathrm{hr}$. $\mathrm{Cr}_{2}\left(\mathrm{O}_{3}\right.$ $(18$ wt $\%)-\mathrm{Al}_{2} \mathrm{O}_{3}$ was a commercial catalyst. Before introduction into the reactor it was heated in a manner similar to $\mathrm{Re}-\mathrm{Al}_{2} \mathrm{O}_{3}$. The catalysts were pretreated in situ as follows: Pt-fluorided $\mathrm{Al}_{2} \mathrm{O}_{3}$ was heated in a flow of purified $\mathrm{H}_{2}$ at $475^{\circ} \mathrm{C}$ for $2 \mathrm{hr} ; \mathrm{Pt}-\mathrm{Nl}_{2} \mathrm{O}_{3}, \mathrm{Pt}-\mathrm{SiO}, \mathrm{Pt}-\mathrm{C}$ were heated in a stream of $\mathrm{H}_{2}$ at $370^{\circ}$ for $1 \mathrm{hr}$. The pretreatment of $\mathrm{Cr}_{2} \mathrm{O}_{3}$ and $\mathrm{Re}-\mathrm{Cr}_{2} \mathrm{O}_{3}$ consisted in a temperature rise at a rate of $50^{\circ} \mathrm{C} / \mathrm{hr}$ in a stream of purified $\mathrm{H}_{2}$ up to $300^{\circ} \mathrm{C}$. A hove this temperature, $\mathrm{H}_{2}$ was replaced with purified $\mathrm{N}_{2}$ up till $400^{\circ} \mathrm{C}$. Re$\mathrm{Al}_{2} \mathrm{O}_{3}$ was treated in a stream of $\mathrm{H}_{2}$ at $400^{\circ} \mathrm{C}$ for $2 \mathrm{hr}$. One batch of $\mathrm{Cr}_{2} \mathrm{O}_{3}-\mathrm{Al}_{2} \mathrm{O}_{3}$ was treated similarly, while in a sccond batch, $\mathrm{H}_{2}$ was replaced by $\mathrm{O}_{2}$.

Research grade hydrocarbons were used and high purity He was employed as hydrocarbon carrier. A $39.1-\mathrm{mg}$ portion $(0.50$ $\mathrm{mCi}$ ) of $\mathrm{C}-14 \mathrm{CHA}$ (radioactive purity $99.5 \%$ ) was diluted with $60 \mathrm{~cm}^{3}$ of nonradioactive CHA to prepare a stock solution of radioactive CHA.

\section{Procedure}

The rate of reaction (1) was studied in a flow system al atmospheric pressure. Metered streams of hydrocarbons were fed to the reactor containing the catalyst. Samples from the exit stream were fractionated by gas ehromatography, and radioactive analysis was carried out on the fractions 
by liquid scintillation techniques. Detailed information on the experimental setup has already been published (1). The experimental conditions were carefully chosen so that in the exit stream only the hydrocarbons fed to the reactor were detected with no interference from isomerization, dehydrogenation, aromatization, and cracking products. These were easily formed outside the ranges of the experimental conditions employed. The $p_{\mathrm{H}_{2}}$ corresponding to the various gas phase equilibria,

$$
\mathrm{C}_{6} \mathrm{H}_{12}(\mathrm{~g})+\mathrm{H}_{2}(\mathrm{~g}) \rightleftharpoons \mathrm{C}_{8} \mathrm{H}_{14}(\mathrm{~g}),
$$

was in the range $1 \times 10^{-1}-10^{-3}$ Torr and the establishment of gas-surface equilibrium during the course of reaction (1) was inferred from the invariability of the hydrocarbon feed as it passed through the catalyst bed and from the reversibility and reproductibility of the results. In blank runs performed with the empty reactor, the reaction conversion was $<0.05 \%$. Results were considered significant only when conversions $\geq 1 \%$ wcre obtained. In most of the runs reported in the next section, the reaction conversions varied between 5 to $10 \%$. The error in the value of the rate constants was estimated between 20 and $30 \%$, depending on the conversion level, while that in the exponent $m$ (Eq. (5)) about $5 \%$.

\section{Results}

As discussed previously (1), the rate of reaction step (1a) is equal to that of reaction (1), and it is given by:

$$
\frac{1}{w} \frac{d n_{* \mathrm{C}_{b}}}{d t}=k_{c} p_{* \mathrm{CHA}}-k^{\prime}{ }_{c} p_{*_{\mathrm{C}_{s}}}
$$

where $n_{*_{C G}}$ are the moles of ${ }^{*} \mathrm{C}_{6}$ formed and $k_{c}, k_{c}^{\prime}$, the rate coefficients of forward and reverse step (1a). Integration of Eq. (3) for a flow reactor gives

$$
k_{c}=\frac{\dot{V}}{w R T} \frac{1}{1+(1 / \beta)} \ln \frac{1}{1-\alpha},
$$

where $w$ is the catalyst weight; $\dot{V}$, volumetric flow rate at temperature $T$;

$$
\beta=\frac{p_{\mathrm{C}_{6}}}{p_{\mathrm{CHA}}},
$$

and the reaction conversion

$$
\alpha=\frac{p_{*_{\mathrm{C}_{6}}}}{\left(p_{*_{\mathrm{C}}}\right)_{e}}=\frac{1+\beta}{\beta} \delta
$$

where

$$
\delta=\frac{p_{* \mathrm{C}_{6}}}{p_{* \mathrm{CHA}}+p_{* \mathrm{C}_{6}}}=\frac{p_{* \mathrm{C}_{6}}}{\left(p_{* \mathrm{CHA}}\right)_{o}} .
$$

The suffixes $o$ and $e$ refer to initial and equilibrium conditions. At constant temperature the rate coefficient, $k_{c}$, is generally dependent upon $\beta, k_{c}=k \beta^{ \pm m}(5)$, where $k$ is the reaction rate constant.

Typical values of $k_{c}$ for reaction (1) at $376^{\circ} \mathrm{C}$ catalyzed by $\mathrm{Pt}-\mathrm{Al}_{2} \mathrm{O}_{3}$ are reported in Fig. 1. The influence of catalyst acidity on the CHA $\rightarrow \mathrm{HA}$ conversion in the temperature range $322-417^{\circ} \mathrm{C}$ is shown in Fig. 2, while Fig. 3 summarizes observations with the same catalyst on the conversion $\mathrm{CHA} \rightarrow 2,3-\mathrm{DMBA}$ at 317 and $417^{\circ} \mathrm{C}$. The results on $\mathrm{Pt}-\mathrm{C}$ and $\mathrm{Pt}-\mathrm{SiO}_{2}$ at 376 and $407^{\circ} \mathrm{C}$ are presented in Fig. 4 . The experi-

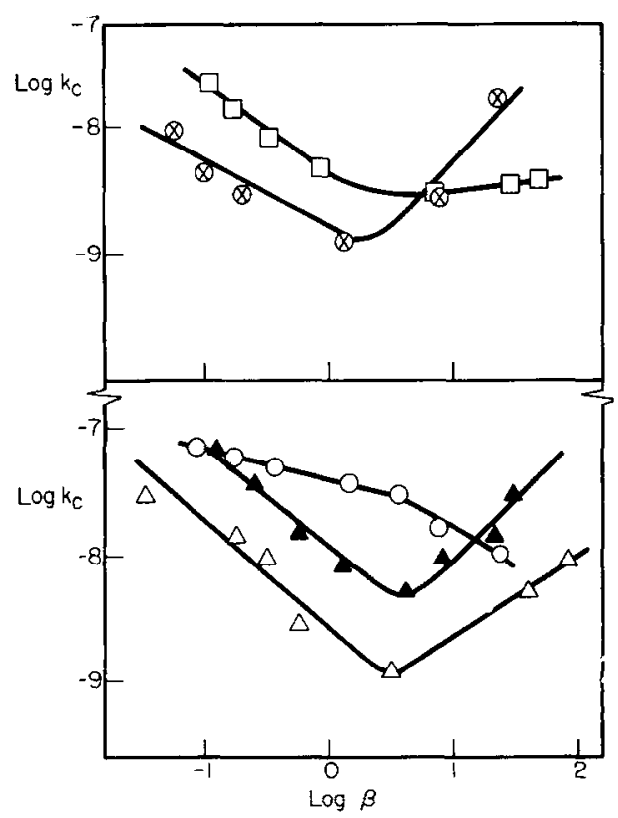

FIG. 1. Effect of $\beta$ on $k_{c}$ for reaction (1) between CHA and 2-MPA $\square, 3-M P A \otimes, 2,2-D M B A ~ \triangle$, 2,3-DMBA $\triangle$, $\mathrm{HA} \odot$. Pt- $\mathrm{Al}_{2} \mathrm{O}_{3}, 376^{\circ} \mathrm{C}$. 


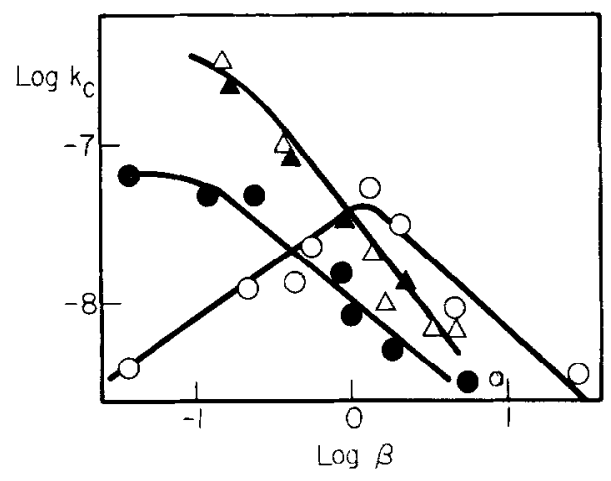

Fig. 2. Effect of $\beta$ on $k_{c}$ for reaction (1) between CHA and $\mathrm{HA}$ on $\mathrm{Pt}(1$ wt $\%)$-fluorided $\mathrm{Al}_{2} \mathrm{O}_{3}$, $322^{\circ} \mathrm{C}, \bigcirc 376^{\circ} \mathrm{C}, \triangle, \Delta 417^{\circ} \mathrm{C}$ (two runs).

mental observations on metal oxide catalysts are reported in Figs. 5, 6, and 7. Figure 5 includes the results on pure $\mathrm{Cr}_{2} \mathrm{O}_{3}$ at 230,292 , and $361^{\circ} \mathrm{C}$; and on $\mathrm{Re}-\mathrm{Cr}_{2} \mathrm{O}_{3}$ at 317 and $412^{\circ} \mathrm{C}$. In Fig. 6 we have collected the observations on $\mathrm{Cr}_{2} \mathrm{O}_{3}-\mathrm{Al}_{2} \mathrm{O}_{3}$ catalysts at $376^{\circ} \mathrm{C}$ pretreated in reducing and oxidizing atmospheres. Figure 7 summarizes the experimental observations at $376^{\circ} \mathrm{C}$ on $\mathrm{Re}-$ $\mathrm{Al}_{2} \mathrm{O}_{3}$ for $\mathrm{CHA} \rightarrow \mathrm{HA}$ and $\mathrm{CHA} \rightarrow 2,3-$ DMBA.

Several runs were performed with the reactor loaded with $\mathrm{CoFe}_{2} \mathrm{O}_{4}$ at different stages of reduction, oxidation, and temperatures up to $400^{\circ} \mathrm{C}$. After more than $200 \mathrm{hr}$ of operation and pretreatments, no significant catalytic activity was detected. Earlier work from this laboratory had shown substantial activity of $\mathrm{CoFe}_{2} \mathrm{O}_{4}$ for the

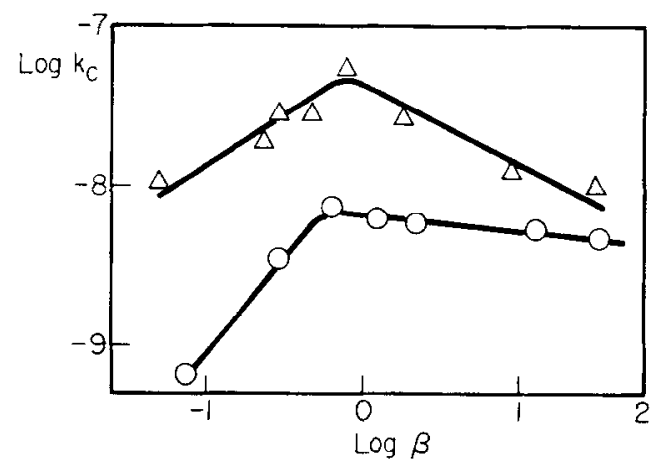

Fia. 3. Effect of $\beta$ on $k_{c}$ for reaction (1) between CHA and 2,3-DMBA on Pt-fluorided $\mathrm{Al}_{2} \mathrm{O}_{3}, \mathrm{O}$ $317^{\circ} \mathrm{C}, \triangle 417^{\circ} \mathrm{C}$.

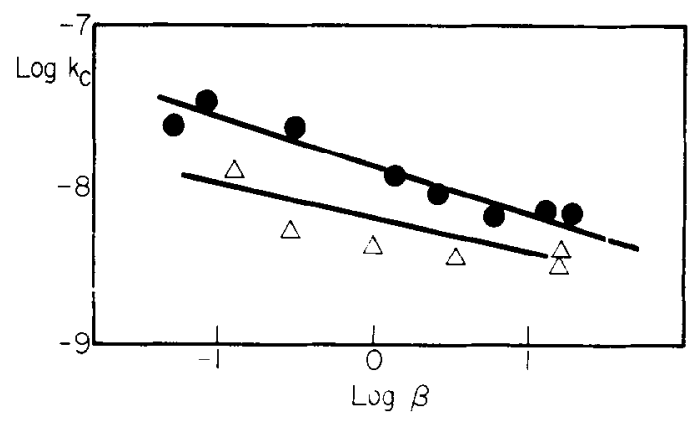

FIG. 4. Eiffect of $\beta$ on $k_{\Delta}$ for reaction (1) between $\mathrm{CHA}$ and $\mathrm{HA}, \mathrm{Pt}-\mathrm{C}, 376^{\circ} \mathrm{C} ; \triangle \mathrm{Pt}-\mathrm{SiO}_{2}, 407^{\circ} \mathrm{C}$.

$\mathrm{H}_{2}-\mathrm{D}_{2}$ exchange reaction (4). Similarly, no appreciable conversion was found on $\mathrm{Al}_{2} \mathrm{O}_{3}$.

\section{Discussion}

The significant experimental results presented in the previous section are:

1. Conversions up to $10 \%$ were obtained for reaction (1) in the temperature range $230-412^{\circ} \mathrm{C}$ and contact times $10-25$ sec on Pt and metal oxides supported and not supported, acidified and not acidified.

2. In all cases investigated, the isothermal reaction coefficient, $k_{c}$, was found dependent upon the ratio of the hydrocarbon partial pressures. The analytical relation and its sign varied with the nature

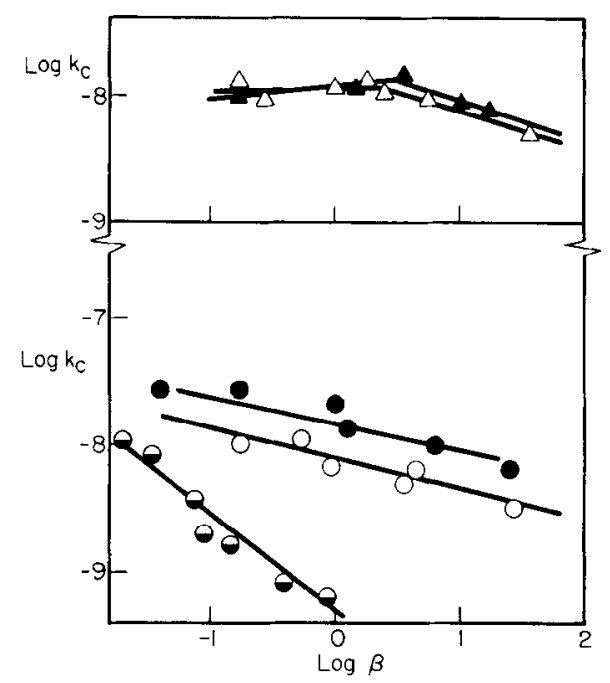

Fig. 5. Effect of $\beta$ on $k_{c}$ for reaction (1) between $\mathrm{CHA}$ and $\mathrm{HA}$ on $\mathrm{Cr}_{2} \mathrm{O}_{s}, 230^{\circ} \mathrm{C}, \bigcirc 292^{\circ} \mathrm{C}$,

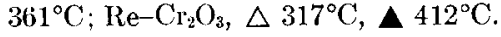




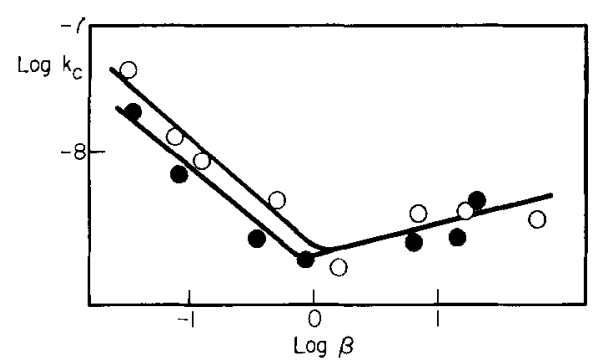

Fig. 6. Effect of $\beta$ on $k_{c}$ for reaction (1) between $\mathrm{CHA}$ and $\mathrm{HA}$ on $\mathrm{Cr}_{2} \mathrm{O}_{3}-\mathrm{Al}_{2} \mathrm{O}_{3}, 376^{\circ} \mathrm{C}$; $\bigcirc \mathrm{H}_{2}$ pretreatment; $\mathrm{O}_{2}$ pretreatment.

of the hexane isomer, catalyst, temperature, and acidity.

3. On nonacidified $\mathrm{Pt}$, the rate constant for the conversion $\mathrm{CHA} \rightarrow \mathrm{HA}$ was found to be higher than that to the other hexanes tested, while no such difference was observed on acidified $\mathrm{Pt}$ or oxide catalysts.

We shall discuss the implications that these findings have in regard to the following topics: (a) nature of the reactive surface centers, (b) relation between the latter and the reaction intermediate, and (c) influence of molecular configuration on the rate of reaction (1).

\section{Nature of Surface Center}

Let us consider Pt catalysts first. We shall assume that under the conditions of reaction (1) a surface layer containing $\mathrm{Pt}$ and $\mathrm{H}$ is formed with a stoichiometric composition $\mathrm{PtH}_{x}$. We shall further assume that the defect structure of the layer may be described by reactions involving two types of atomic defects, namely hydrogen, $V_{\mathrm{H}}$, and $\mathrm{Pt}, V_{\mathrm{Pt}}$, lattice vacancies and electronic defects, namely defect $\mathrm{e}^{+}$, and excess

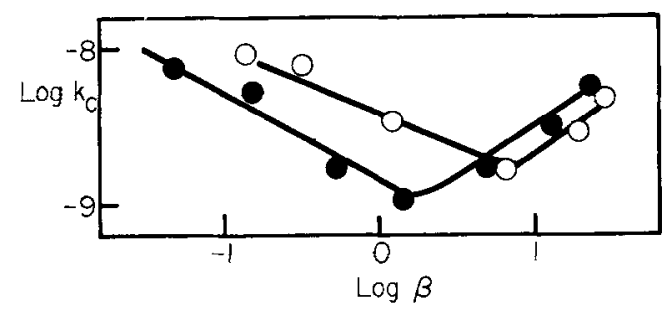

FIG. 7. Effect of $\beta$ on $k_{c}$ for reaction (1) on $\mathrm{Re}^{-}$ $\mathrm{Al}_{2} \mathrm{O}_{3}, 376^{\circ} \mathrm{C} \bigcirc \mathrm{CHA} \rightarrow \mathrm{HA}, \quad \mathrm{CHA} \rightarrow 2,3-$ DMBA. $e^{-}$, electrons. The details of the bonding between $\mathrm{Pt}$ and $\mathbf{H}$ in the layer cannot be definitively pictured, but we shall consider that a negative charge is localized on the $\mathrm{H}$. Previous studies in $\mathrm{H}_{2}$ atomsphere have shown that a stable surface structure is formed upon heating a Pt(100) surfacc (5), and the presence of hydridic hydrogen (rather than $\mathrm{H}^{+}$) in this layer seems more consistent with recent Leed results on $\mathrm{H}_{2}$ adsorption on metals $(6)$ and with theoretical models (7). If this model of a Pt surface coexisting with a $\mathrm{CHA}-\mathrm{C}_{6}$ atmosphere is accepted, the chemical reactivity of the layer may be described by defect reaclions, among which the significant ones are the electronic equilibrium between $\mathrm{e}^{+}$and $\mathrm{e}^{-}$, viz.,

$$
0=\mathrm{e}^{+}+\mathrm{e}^{-}
$$

the formation of hydrogen and $\mathrm{Pt}$ vacancies,

$$
0=x V_{\mathrm{It}}+V_{\mathrm{Pt}}
$$

and the ionization of the vacancies,

$$
V_{\mathrm{Pt}}=V_{\mathbf{P t}^{-x}}+x \mathrm{e}^{-},
$$

and

$$
V_{\mathrm{H}}=V_{\mathrm{H}^{+}}+\mathrm{e}^{-} .
$$

The positive charge on $V_{\mathrm{H}^{+}}$results from the assumption of the presence of hydridic hydrogen in the $\mathrm{PtH}_{x}$ layer. In addition, hydrogen vacancies may be formed in the $\mathrm{PtH}_{x}$ layer through the equilibrium with the gas phase containing CHA and $\mathrm{C}_{6}$,

$$
\mathrm{CHA}=\mathrm{C}_{6}+2 V_{\mathrm{H}} .
$$

The general expression of the electroneutrality condition among all the charged defects considered above is

$$
\left[\mathrm{e}^{+}\right]+\left[V_{\mathbf{H}^{+}}\right]=\left[\mathrm{e}^{-}\right]+\left[\mathrm{Pt}^{-x}\right] \text {. }
$$

Equation (11) may be simplified by considering three limiting cases: at low values of $\beta$, hydrogen vacancies and electrons will predominate or $\left[\mathrm{e}^{+}\right] \ll\left[V_{\mathrm{H}^{+}}\right]$and $\left[V_{\mathrm{Pt}^{-x}}\right]$ $\ll\left[\mathrm{e}^{-}\right]$. Equation (11) approximates then to

* The defect reactions are written following the symbolism in F. A. Kroger, "Chemistry of Imperfect Crystals" Wiley, New York, 1964. 


$$
\left[V_{\mathbf{H}^{+}}{ }^{+} \cong\left[\mathrm{e}^{-}\right]\right.
$$

Upon increasing the value of $\beta$, the approximations are

$$
\left[V_{\mathrm{H}}^{+}\right] \cong\left[V_{\mathrm{Pt}^{-x}}\right] \text {, }
$$

and

$$
\left[\mathrm{e}^{+}\right] \cong\left[V_{\mathbf{P t}^{-}}{ }^{-x}\right] .
$$

Through the application of the mass action expression to reactions (6) and (10) and solution of the corresponding equations, it is possible to compute the values of the differential ratio

$$
\frac{\partial \ln [\text { defect }]}{\partial \ln \beta}=n
$$

for the three ranges of approximation of Eq. (11). The value of $x$ for a PtH layer resulting from $\mathrm{H}_{2}$ adsorption on $\mathrm{Pt}$ is presently under scrutiny (8). Generally $1 \leq x$ $\leq 2$. Taking $x=1$, the calculated values of $n$ are collected in Table 1.

The interpretation of the experimental results will be made by considering the defects of the $\mathrm{PtH}$ layer reported in Table 1 as sites for the catalytic activity of the surface towards reaction (1). The search for the correct type of defect among those listed is made by comparing the analytical dependence of each type of defect upon $\beta$ (Table 1) with the experimentally measured dependence of $k_{e}$ upon $\beta$.

The experimental results have shown that for nonacidified $\mathrm{Pt}$, the function $k_{e}=$

TABLE 1

$$
\begin{gathered}
\text { Values of } \frac{\partial \ln [\text { Defect }]}{\partial \ln \beta}=N \text { for Various } \\
\text { Approximations of EQ. (11) } \\
\text { IN PtH LAYER }
\end{gathered}
$$

\begin{tabular}{lccc}
\hline Range & $\begin{array}{c}\mathrm{I} \\
{\left[V_{\mathrm{H}^{+}}\right]}\end{array}$ & $\begin{array}{c}\mathrm{II} \\
{\left[V_{\mathrm{H}^{+}}\right]}\end{array}$ & $\begin{array}{l}\text { III } \\
{\left[\mathrm{e}^{-}\right]}\end{array}$ \\
Defect & $\cong\left[\mathrm{e}^{-}\right]$ & $\cong\left[\boldsymbol{V}_{\left.\mathrm{Pt}^{-}\right]}\right.$ & $\cong\left[\boldsymbol{V}_{\left.\mathrm{Pt}^{-}\right]}\right]$ \\
\hline $\mathrm{e}^{+}$ & $\begin{array}{l}\frac{1}{4} \\
\mathrm{e}^{-}\end{array}$ & 0 & $-\frac{1}{4}$ \\
$V_{\mathrm{H}}$ & $-\frac{1}{2}$ & 0 & $\frac{1}{4}$ \\
$V_{\mathrm{Pt}_{\mathrm{t}}}$ & $-\frac{1}{2}$ & $-\frac{1}{2}$ & $-\frac{1}{2}$ \\
$V_{\mathbf{H}^{+}}$ & $-\frac{1}{4}$ & $-\frac{1}{2}$ & $-\frac{x}{2}$ \\
$V_{\mathbf{P t}^{-x}}$ & $-\frac{3}{4}$ & $-\frac{1}{2}$ & $-\frac{3}{4}$ \\
\hline
\end{tabular}

$f(\beta)$ had a minimum (except for $\mathrm{CHA} \rightarrow$ HA, Fig. 1) and for acidified, a maximum (except at $417^{\circ} \mathrm{C}$, Fig. 3). From Table 1, it is apparent that a minimum in surface activity is obtained when the preponderant reactive sites are electrons while a maximum is consistent with electron holes. It is interesting to remark that no ionic or atomic defect, among those taken into consideration, induces reactivity patterns with minima or maxima.

Writing the generalized form of the ratedetermining step of reaction step (1a) catalyzed by acidified $\mathrm{Pt}$ :

$$
{ }^{*} \mathrm{CHA}(\mathrm{g})+y \mathrm{e}^{+} \rightarrow{ }^{*} \mathrm{CHA} \cdot y \mathrm{e}^{+}(\mathrm{s}),
$$

and for nonacidified $\mathrm{Pt}$ :

$$
{ }^{*} \mathrm{CHA}(\mathrm{g})+y^{\prime} \mathrm{e}^{-} \rightarrow{ }^{*} \mathrm{CHA} \cdot y \mathrm{e}^{-}(\mathrm{s}),
$$

where $y, y^{\prime}>0$ and substituting for $\left[\mathrm{e}^{+}\right]$ and $\left[\mathrm{e}^{-}\right]$the corresponding functions listed in Table 1 , it is found that for increasing $\beta$, the rate of reaction steps (12) and (13) will have a maximum and a minimum, respectively, as a function of $\beta$. Since $k_{c}=$ $k \cdot \beta^{ \pm m}=k\left[\mathrm{e}^{+}\right]^{y}=\beta^{ \pm n y}$ (or $k\left[\mathrm{e}^{-}\right]^{y^{\prime}}$ ), the correct values of $y$ and $y^{\prime}$ may be obtained by comparing the theoretical values of $n$ (Table 1) with the slope $m$ of the experimental plots $\ln k_{c}$ vs. $\ln \beta$ (Figs. 1-7). For nonacidified $\mathrm{Pt}$ at $376^{\circ} \mathrm{C}$, the results of the comparison are summarized in Table 2 and in Table 3 for acidified Pt.

According to the interpretation here suggested, the inversion in surface reactivity with $\beta$ is the result of the influence of the ratio $\beta$ upon the defect electron chemistry of the surface layer and, particularly, on the specific form of the intrinsic defect reaction (7).

Comparison of the results of Tables 2 and 3 shows that reaction (1) took place in a drastically different fashion when acidified $\mathrm{Al}_{2} \mathrm{O}_{3}$ replaced nonacidified $\mathrm{Al}_{2} \mathrm{O}_{3}$ as $\mathrm{Pt}$ support. In fact, the variation of the sign of $m$ with $\beta$ is opposite for the two conditions of the support. Also, the type of the hexane isomer had a definite influence on the rate of reaction (1) for nonacidified $\mathrm{Pt}$, indicating that the nature of the intermediate species is altered by the pres- 
TABLE 2

Number of Surface Centers, $e^{-}$, Pler Cha Molecule Activi in the Conversion of Cha to Hexanes, Nonacidifikd $\mathrm{Pt}-\mathrm{Al}_{2} \mathrm{O}_{3}, 376^{\circ} \mathrm{C}$

\begin{tabular}{ccll}
\hline Hexane & $y^{\prime}=\frac{\text { Surface center }}{\text { CHA molecule }}$ & $y^{\prime} \cdot \frac{\partial \ln \left[\mathrm{e}^{-}\right]^{a}}{\partial \ln \beta}$ & $\frac{\partial \ln k_{c}^{a}}{\partial \ln \beta}$ \\
\hline HA & 1 & -0.25 & -0.34 \\
2-MPA & 3 & -0.75 to 0 & -0.70 to 0.1 \\
3 -MPA & 3 & -0.75 to 0.75 & -0.66 to 0.70 \\
$2,2-1 \mathrm{DMBA}$ & $4-3$ & -1.0 to 0.75 & -0.10 to 0.75 \\
$2,3-\mathrm{DMBA}$ & 4 & -1.0 to 1.0 & -0.90 to 1.0 \\
HA $^{b}$ & 1 & -0.25 to 0 & -0.29 to 0.1 \\
HA $^{c}$ & $2-1$ & -0.50 to 0.25 & -0.5 to 0.3 \\
\hline
\end{tabular}

a Values given for increasing $\beta$.

${ }^{b} \mathrm{Pt}-\mathrm{C}$.

c $\mathrm{Pt}-\mathrm{SiO}_{2}$.

ence of high acidity in or around Pt. For $\mathrm{Pt}$ supported on nonacidified $\mathrm{Al}_{2} \mathrm{O}_{3}$, the hexanes may be divided into three groups, according to the values of $y^{\prime}$ (Table 2), (a) HA with $y^{\prime}=1$, (b) 2- and 3-MPA with $y^{\prime} \cong 3$, and (c) 2,2- and 2,3-DMBA with $3 \leq y^{\prime} \leq 4$. In terms of the surface model employed, these values indicate that the reaction intermediate had, on the average, one, three, and between three and four bonding attachments to the catalyst surface. This suggests three different adsorbed intermediates of CHA: (a) with one surface bonding and probably retaining the ring configuration of $\mathrm{CHA}$, which can only lead to HA; but HA may be obtained also from other adsorbed intermediates; (b) with three surface bondings and a cyclopentane configuration, which can only lead to methylpentanes; and (c) with a number of surface bondings between 3 and 4 and a cyclobutane configuration. 'This intermedi- ate leads to 2,3-DMBA and, via alkyl shift, to 2,2-DMBA. These reaction paths imply that ring opening and contracting can take place with relative ease under the experimental conditions employed. Experimental evidence, gathered in our laboratory, independently from this study, strongly support this conclusion.

In the presence of large amounts of acidity these differences in reaction intermediates were obscured by the presence of a new reaction path. It is known that high catalyst acidity promotes conditions for isomerization and fragmentation reactions. A strong electron donation to the metal from the adsorbate sets up an electron deficiency and a weakening of the bonds in the former similar to that determining skeletal rearrangements in carbonium ions. It is, then, likely that on Pt-fluorided $\mathrm{Al}_{2} \mathrm{O}_{3}$, CHA underwent ring opening and broad isomerization and consequently, no larger

TABLE 3

Number of Surface Centers, $e^{+}$, Per Cha Molecule Activi in the Conversion of Cha to Hexanes, Pt-Fluorided $\mathrm{Al}_{2} \mathrm{O}_{3}$

\begin{tabular}{ccccc}
\hline Hexane & $\begin{array}{c}\text { Temp } \\
{ }^{\circ} \mathrm{C}\end{array}$ & $y=\frac{\text { Surface center }}{\text { CHA molecule }}$ & $y \cdot \frac{\partial \ln \left[\mathrm{e}^{+}\right]^{a}}{\partial \ln \beta}$ & $\frac{\partial \ln k_{c}{ }^{a}}{\partial \ln \beta}$ \\
\hline HA & 322 & 3 & $0-0.75$ & 0 to 0.70 \\
HA & 363 & $3-4$ & 0.75 to -1.0 & 0.62 to -0.9 \\
HA & 417 & 4 & -1.00 & -1.2 \\
$2,3-$ DMBA & 317 & 3 & $0.75-0$ & $0.75-0$ \\
$2,3-D M B A$ & 417 & 4 & 1.0 to -1.0 & 1.0 to -1.0 \\
\hline
\end{tabular}

a Values given for increasing $\beta$. 
differences in behavior should be expected among the various hexane isomers. This is consistent with the results of Table 3. Questions as to how the acidity influenced the reactive sites in the $\mathrm{Pt}$ layer and the defect chemistry of the latter, or whether this kind of carbonium ion intermediate was formed directly on the acidic sites of the carrier, cannot be answered at present. The previous conclusions are consistent with studies on the hydrogenolysis of methylcyclopentane and isomerization of $n$ hexane on $\mathrm{Pt}-\mathrm{Al}_{2} \mathrm{O}_{3}$ (9). These investigations showed that the initial product distributions were identical for both reactions and suggested that $\alpha, \beta$, and $\gamma$ triadsorbed species were responsibile for the formation of a methylcyclopentane intermediate. It is of course tempting to relate this to the finding that $y^{\prime}=3$ for 2 - and 3-MPA as observed in this work. It should be remembered, however, that the studies on hydrogenolysis were carried out in the presence of $\mathrm{H}_{2}$, and it is not known how much the conditions at the surface are altered by this. For the formation of adsorbed cyclobutane intermediates during the course of reaction (1) with $\mathrm{C}_{6}$ being 2,2-DMBA or 2,3-DMBA, there is support from work on the hydrogenolysis of substituted cyclobutanes on Pt-- $\mathrm{Al}_{2} \mathrm{O}_{2}$ (10). In this instance, tri- and tetraadsorbed species were considered responsible for the hydrogenolysis. It is again tempting to relate this suggestion with our findings that 3 $\leq y^{\prime} \leq 4$ for the $\mathrm{CHA} \rightarrow 2,2-(2,3-) \mathrm{DMBA}$ conversion.

To sum up, the results on $\mathrm{Pt}$ strongly suggest the formation of cyclic intermediates on nonacidified $\mathrm{Pt}$ during the course of reaction (1). Their formation took place at the $\mathrm{Pt}$ surface, as it is clearly demonstrated by the fact that $\mathrm{Pt}-\mathrm{Al}_{2} \mathrm{O}_{3}, \mathrm{Pt}-\mathrm{C}$, and $\mathrm{Pt}-\mathrm{SiO}_{2}$ have almost similar behavior and that activity sets in at temperatures as low as $280^{\circ} \mathrm{C}$. Thus, something similar to an isomerization reaction occurred directly on $\mathrm{Pt}$ with no influence from $\mathrm{Al}_{2} \mathrm{O}_{3}$. This conclusion should be viewed together with the increased list of studies in which Pt was found to catalyze isomerizations and aro- matization $(9,11,12)$ and cannot, therefore, be simply considered a (de)hydrogenation agent.

In the case of the metal oxide catalysts tested, the presence of oxygen as an active component necessitates a surface model different from that employed in the case of supported Pt. Let us consider a metal oxide $\mathrm{MeO}_{z / 2}$, composed of $\mathrm{Me}^{+z}$ and $\mathrm{O}^{-2}$ ions and $z=1,2$. At the surface, in addition to vacant metal $\left(V_{\mathrm{Me}}\right)$ and oxygen $\left(V_{0}\right)$ sites. we assume that alkane adcorption gencratcs $\mathrm{OH}$ groups; viz.,

$$
\text { C } \mathrm{HA}+2 \mathrm{OH}=\mathrm{C}_{6}+\text { oxide. }
$$

$\mathrm{OH}$ groups may be incorporated in the surface lattice substitutionally to an $\mathrm{O}^{-2}$ ion or interstitially. In the former instance. they correspond to $\mathrm{OH}^{+}$ions, while in the latter, to $\mathrm{OH}^{-}$ions. The ionization equilibria of the $\mathrm{OH}$ groups are then;

$$
\mathrm{OH}^{+}+\mathrm{e}^{-}=\mathrm{OH}
$$

and

$$
\mathrm{OH}^{-}+\mathrm{e}^{+}=\mathrm{OH} \text {. }
$$

The surface structure of chromia and its relation to chemisorption of gases has been recently reviewed in detail (13). It was suggested that the heterolytic dissociative adsorption of hydrocarbons occurs on chromia via coordinatively unsaturated adjacent pairs of $\mathrm{Cr}^{+3}$ and $\mathrm{O}^{-2}$; the latter ion being transformed into $\mathrm{OH}^{-}$. This is consistent with the model of alkane adsorption on oxides here proposcd. Since it is quite likely that cooperative electronic interactions are present in the surface of metal oxides, the charge on the $\mathrm{OH}$ groups may be positive or negative, and not always positive as previously suggested (13) for chromia.

We shall assume that in addition to OII, $\mathrm{OH}^{+}$, and $\mathrm{OH}^{-}$groups, and defect and excess electrons, the surface layer comprises vacant oxygen, $V_{\mathbf{0}}$, and chromium, $V_{\text {Me }}$, sites, which are related through their formation equilibrium reaction,

$$
\frac{z}{2} V_{\mathrm{o}}+V_{\mathrm{Me}}=0 .
$$


The ionization equilibria for $V_{\text {Me }}$ and $V_{0}$ are

$$
V_{\mathrm{Me}^{-z}}+z \mathrm{e}^{+}=V_{\mathrm{Me}},
$$

and

$$
V_{o}{ }^{+2}+2 \mathrm{e}^{-}=V_{o},
$$

respectively. Finally, there is the possibility that ionization of surface $\mathrm{OH}$ groups takes place by electron transfer to and from $V_{0}$ and $V_{\mathrm{Me}}$, viz.,

$$
z \mathrm{OH}^{+}+V_{\mathrm{Me}^{-z}}=z \mathrm{OH},
$$

and

$$
z \mathrm{OH}^{-}+\frac{z}{2} V_{\mathrm{o}^{+2}}=z \mathrm{OH} .
$$

As carried out in the case of $\mathrm{Pt}$, the general expression of the electroneutrality condition,

$$
\begin{aligned}
{\left[\mathrm{OH}^{+}\right]+\left[\mathrm{e}^{+}\right]+\left[V_{\mathrm{o}}^{+2}\right]=\left[\mathrm{e}^{-}\right] } & +\left[V_{\left.\mathrm{Me}^{-2}\right]}\right. \\
+ & {\left[\mathrm{OH}^{-}\right], }
\end{aligned}
$$

may be simplified according to the value of $\beta$. It is reasonable to assume that at low $\beta$, alkane adsorption took place through the formation of substitutional $\mathrm{OH}^{+}$groups, reverting to interstitial $\mathrm{OH}^{-}$at higher $\beta$ 's. The correct value of $z$ which describes the metal ions in $\mathrm{Cr}_{2} \mathrm{O}_{3}$ and $\mathrm{Re}_{2} \mathrm{O}_{3}$ at the surface under reactive conditions is unknown. Taking $z=3$, and applying the mass action expression to reactions (14)-(21), it is possible to calculate the values of

$$
\frac{\partial \ln [\text { defect }]}{\partial \ln \beta}
$$

for a few significant ranges of approximation of Eq. (22). These are reported in
Table 4. The interpretation of the experimental results on the rate of reaction (1) on metal oxide catalysts is carried out in a manner similar to that employed for sul'ported Pt catalyst.s.

Except for pure $\mathrm{Cr}_{2} \mathrm{O}_{3}$, the exrerimental results on the metal oxides tested show that the function $k_{c}=f(\beta)$ had a minimum. In terms of the mors empioyed, surface centers of the type $\mathrm{e}^{+}$and $\mathrm{V}_{0}{ }^{+2}$ provide a surface reactivity possessing a minimum with varying $\beta$. Since the results do not permit a cleur differentiation between the two types, we shall consider only $\mathrm{e}^{+}$sites and P. sume a rate-determining step for reaction (1) on metal oxide catalysts simiar to reaction step (12). By comparing the values of

$$
\frac{\partial \ln \left[\mathrm{e}^{+}\right]}{\partial \ln \beta}
$$

and

$$
\frac{\partial \ln k_{c}}{\partial \ln \beta}
$$

it is possible to calculate the number of surface centers per CHA molecule, $y$, in each case, investigated. The results of the computations are collected in Table 5.

The pattern of reactivity emerging from the results of Table 5 reproduces broadly the features observed in the case of acidified Pt. In fact, the formulation of the ratedetermining step is similar and in both instances positively charged reaction intermediates are indicated. In general, a tendency to higher fragmentation upon adsorption of CHA was present in metal oxides.

TABLE 4

Values of $\frac{\partial \ln [\text { Dfifect }]}{\partial \ln \beta}=N^{\prime}$ for Various Approximations of Eq. (22) in Metal Oxide LaYer in EQuilibrium with a CHA + $\mathrm{C}_{6}$ Mixture

\begin{tabular}{cccccc}
\hline Range & I & II & III & IV & V \\
Defect & {$\left[\mathrm{OH}^{+}\right] \cong\left[\mathrm{e}^{-}\right]$} & {$\left[\mathrm{OH}^{+}\right] \cong\left[V_{\left.\mathrm{Me}^{-3}\right]}\right]\left[\mathrm{OH}^{+}\right] \cong\left[\mathrm{OH}^{-}\right]$} & {$[\mathrm{OH}-] \cong\left[V_{\mathrm{O}}^{+2}\right]$} & {$\left[\mathrm{e}^{+}\right] \cong\left[\mathrm{OH}^{-}\right]$} \\
\hline $\mathrm{e}^{+}$ & $-1 / 4$ & $-1 / 8$ & 0 & $-1 / 10$ & $1 / 4$ \\
$\mathrm{e}^{-}$ & $1 / 4$ & $1 / 8$ & 0 & $1 / 10$ & $-1 / 4$ \\
$V_{\mathrm{o}}^{+2}$ & $-1 / 2$ & $1 / 4$ & 0 & $3 / 5$ & $1 / 2$ \\
$V_{\mathrm{Me}}{ }^{-3}$ & $3 / 4$ & $9 / 8$ & 0 & $-3 / 5$ & 0 \\
$V_{\mathrm{Me}}$ & 0 & $3 / 4$ & 0 & $3 / 5$ & 0 \\
\hline
\end{tabular}


TABLE 5

Number of Surface: Centers, e ${ }^{+}$, per Cha Molfcule Active in the Conversion of Cha to Hexanis, Metal Oxide Catalysts

\begin{tabular}{|c|c|c|c|c|c|}
\hline Catalyst & Hydrocarbon & $\begin{array}{c}\text { Temp } \\
{ }^{\circ} \mathrm{C}\end{array}$ & $y=\frac{\text { Surface centers }}{\text { CHA molecule }}$ & $y \cdot \frac{\partial \ln \left[\mathrm{e}^{+}\right]}{\partial \ln \beta}$ & $\frac{\partial \ln k_{c}}{\partial \ln \beta}$ \\
\hline $\mathrm{Cr}_{2} \mathrm{O}_{3}$ & HA & 230 & 1 & $-0.25^{a}$ & -0.20 \\
\hline $\mathrm{Cr}_{2} \mathrm{O}_{3}$ & $\mathrm{HA}$ & 292 & 1 & $-0.25^{a}$ & -0.24 \\
\hline $\mathrm{Cr}_{2} \mathrm{O}_{3}$ & $\mathrm{HA}$ & 361 & 3 & $-0.75^{a}$ & -0.75 \\
\hline $\mathrm{Re}^{-} \mathrm{Cr}_{2} \mathrm{O}_{3}$ & $\mathrm{HA}$ & 317 & 1 & $-0.25^{n}$ & -0.30 \\
\hline IRe $-\mathrm{Cr}_{2} \mathrm{O}_{3}$ & HA & 412 & $1-2$ & -0.25 to -0.50 & -0.33 \\
\hline $\mathrm{Re}-\mathrm{Al}_{2} \mathrm{O}_{3}$ & 2,3-I)MBA & 376 & 2 & -0.2 to 0.5 & -0.50 to 0.55 \\
\hline $\mathrm{Re}-\mathrm{Al}_{2} \mathrm{O}_{3}$ & HA & 376 & $2-3$ & -0.2 to 0.75 & -0.44 to 0.80 \\
\hline $\mathrm{Cr}_{2} \mathrm{O}_{3}-\mathrm{Al}_{2} \mathrm{O}_{3}{ }^{b}$ & $\mathrm{HA}$ & 376 & $3-1$ & -0.75 to 0.25 & -0.80 to 0.25 \\
\hline $\mathrm{Cr}_{2} \mathrm{O}_{3}-\mathrm{Al}_{2} \mathrm{O}_{3} \mathrm{r}$ & $\mathrm{HA}$ & 376 & $3-1$ & -0.75 to 0.25 & -0.80 to 025 \\
\hline
\end{tabular}

"Range I only (Table 4).

${ }^{b}$ Oxygen treated.

${ }^{c}$ Hydrogen treated.

The fragmentation increased with temperature, as expected. 'The reactivity of $\mathrm{Cr}_{2} \mathrm{O}_{3}$ was modified by the addition of $\mathrm{Re}$ which at higher temperatures had a marked effect in decreasing the fragmentation tendency of pure $\mathrm{Cr}_{2} \mathrm{O}_{3}$. If this interpretation is correct, $\mathrm{Re}_{-}-\mathrm{Cr}_{2} \mathrm{O}_{3}$ catalysts should be more selective and stable in hydrolytic hydrocarbon conversion than pure $\mathrm{Cr}_{2} \mathrm{O}_{3} \cdot \mathrm{O}_{2}$ and $\mathrm{H}_{2}$ pretreatment did not alter appreciably the reactivity of $\mathrm{Cr}_{2} \mathrm{O}_{3}-\mathrm{Al}_{2} \mathrm{O}_{3}$. Earlier work had indicated that acid properties could be introduced in $\mathrm{Cr}_{2} \mathrm{O}_{3}$ by $\mathrm{O}_{2}$ treatment (14).

\section{Reaction Rate}

The rate of the surface interaction is characterized by the reaction rate constant, $k$, defined by Eq. (5). The influence on $k$ of the hexane isomer, at $376^{\circ} \mathrm{C}$, for $\mathrm{Pt}-$ $\mathrm{Al}_{2} \mathrm{O}_{3}$ and $\mathrm{Re}-\mathrm{Al}_{2} \mathrm{O}_{3}$ catalysts is reported in Table 6.

The order of ease of conversion on $\mathrm{Pt}$ is $\mathrm{HA}>2,3-\mathrm{DMBA}>2$-MPA $>2,2$ $\mathrm{DMBA} \approx 3-\mathrm{MPA}$ with a difference in rate constant of more than an order of magnitude between HA and 3-MPA. Although activity sequences obtained in direct isomerization studies were found to vary with catalyst employed (15), there are some features of the above sequence which are common to those obtained in direct isomerization studies (16). The common points are (a) 2-MP $\Lambda>3-M P \Lambda$, and (b) 2,3-
DMBA $>2,2$-DMBA. In particular, it has always been found easier to convert 2,3DMBA than 2,2-DMBA. This is consistent with the present findings, according to which the conversion of CHA to 2,3-DMBA is almost as fast as that to HA.

TABLE 6

INFIUNCH OF HEXAN ISOMER ON THE RATE Constant, $k$, for Raction (1), $376^{\circ} \mathrm{C}$

\begin{tabular}{|c|c|c|c|}
\hline \multirow[b]{2}{*}{ Catalyst } & \multirow{2}{*}{$\begin{array}{l}\text { Hydro- } \\
\text { carbon }\end{array}$} & \multirow{2}{*}{$l i \cdot 10^{8}$} & \multirow{2}{*}{$\frac{\text { moles }}{\text { g-cat. sec atm }}$} \\
\hline & & & \\
\hline \multirow{4}{*}{$\mathrm{Pt}-\mathrm{Al}_{2} \mathrm{O}_{3}$} & HA & & 2.60 \\
\hline & 2-MPA & & 0.40 \\
\hline & 3-MPA & & 0.20 \\
\hline & 2,2-DMBA & & 0.25 \\
\hline \multirow{3}{*}{$\mathrm{Re}-\mathrm{Al}_{2} \mathrm{O}_{3}$} & 2,3-I)MBA & & 1.25 \\
\hline & $\mathrm{HA}$ & & (). 14 \\
\hline & 2,3-j)MBA & & 0.40 \\
\hline
\end{tabular}

The influence of the support on $k$ may be derived from the results in Figs. 1, 3, 5. The computed values of $k$ are collected in Table 7.

The results show that therc is no large influence of acidity and of catalyst support on the rate constant. The value on $\mathrm{Pt}-\mathrm{SiO}_{2}$ is somewhat lower than that of the others. A characterization of the $P t$ on this catalyst was not carried out, and it is not certain whether the state of the Pt particles in this catalyst was comparable to that of the Pt on the other supports. The experi- 
TABLE 7

INFLUENCE OF THE SUPPORT OF $\mathrm{Pt}(\mathbf{0 . 4 \%})$ ON THE

Rate Constant, $k$, of Reaction (1) BetWeEN CHA AND HA, $376^{\circ} \mathrm{C}$

$k \cdot 10^{8}$

Support

[moles/g-cat sec. atm]

$\begin{array}{cc}\mathrm{Al}_{2} \mathrm{O}_{3} & 2.3 \\ \text { Fluorided } \mathrm{Al}_{2} \mathrm{O}_{3} & 3.2 \\ \text { Graphon }^{n} & 1.45 \\ \mathrm{SiO}_{2}{ }^{6} & 0.63\end{array}$

"One percent $\mathrm{Pt}$.

${ }^{b}$ Five-tenths percent $\mathrm{Pt}, 40 \mathrm{i}^{\circ} \mathrm{C}$.

mental conditions of the present studies were quite different from those commonly employed with bifunctional reforming catalysts and the present results which point to $\mathrm{Pt}$ as carrying the burden of the hydrogen transfer and isomerization steps, do not necessarily invalidate the commonly accepted mechanism of bifunctional calalysis over metal-acid oxide systems. Nevertheless, as already argued, it appears again while considering the kinetic aspect of surface reactivity, that the simple view that the metal serves only as a dehydrogenation catalyst must be accepted with qualification.

For metal oxide catalysts, the values of $k$, calculated from Figs. 5, 6, 7, are reported in Table 8.

The sequence of the rate constants is $\mathrm{Re}-\mathrm{Cr}_{2} \mathrm{O}_{3}>\mathrm{Re}-\mathrm{Al}_{2} \mathrm{O}_{3} \approx \mathrm{Cr}_{2} \mathrm{O}_{3}-\mathrm{Al}_{2} \mathrm{O}_{3}>$ $\mathrm{Cr}_{2} \mathrm{O}_{3}$. An interesting finding is that the addition of $\mathrm{Re}$ to $\mathrm{Cr}_{2} \mathrm{O}_{3}$ increased the ac-

TABLE 8

Rate Congtant, $k$, of Relction (1) Betwein CHA and HA Catalyzed ry Metal Oxidrs, $376^{\circ} \mathrm{C}$

\begin{tabular}{cc}
\hline Catalyst & $\begin{array}{c}k \cdot 10^{8} \\
\text { [moles/g-cat sec. atm] }\end{array}$ \\
\hline $\mathrm{Cr}_{2} \mathrm{O}_{3}$ & 0.032 \\
$\mathrm{Re}^{-}-\mathrm{Cr}_{2} \mathrm{O}_{3}{ }^{a}$ & 1.2 \\
$\mathrm{Cr}_{2} \mathrm{O}_{3}-\mathrm{Al}_{2} \mathrm{O}_{5}{ }^{b}$ & 0.1 \\
$\mathrm{Cr}_{2} \mathrm{O}_{3}-\mathrm{Al}_{2} \mathrm{O}_{3}{ }^{c}$ & 0.2 \\
$\mathrm{Re}-\mathrm{Al}_{2} \mathrm{O}_{3}$ & 0.14
\end{tabular}

a $317^{\circ} \mathrm{C}$.

${ }^{B} \mathrm{O}_{2}$ pretreated.

${ }^{c} \mathrm{H}_{2}$ pretreated. tivity of $\mathrm{Cr}_{2} \mathrm{O}_{3}$ by about two orders of magnitude. This large effect cannot result solely from the function of Re in retarding crystallization of the chromia xerogel, but it must depend upon a definite chemical interaction between the two compounds. The extent to which these results can be translated to predict the behavior of the oxide catalysts for net hydrogenolysis reactions cannot be easily anticipated since no direct and readily comparable tests for these reactions on the catalysts employed in this research have been carried out. But in view of the similarities pointed out before in reaction mechanism and kinetic sequence, there is the likelihood that, in significant aspects, the equilibrium reaction (1) can be considered a test for hydrogenolysis activity. It is, then, tempting to predict that Re- $\mathrm{Cr}_{2} \mathrm{O}_{3}$ should be a superior hydrogenolysis catalyst than $\mathrm{Cr}_{2} \mathrm{O}_{3}$.

For $\mathrm{Cr}_{2} \mathrm{O}_{3}$, there was practically no influence of the atmosphere employed in the pretreatment upon $k$, as it has already been remarked for the effect on $m$ (Table 5).

From the temperature dependence of the rate constant for Pt-fluorided $\mathrm{Al}_{2} \mathrm{O}_{3}$ an activation energy of about $5-6 \mathrm{kcal} / \mathrm{mole}$ was calculated for reaction (1). It should be noted that $\mathrm{Cr}_{2} \mathrm{O}_{3}$ had a negative temperature coefficient (Fig. 5).

\section{Conclustons}

The results of the present investigation cannot be compared directly with previous researches on the dehydrocyclization of paraffins, since the latter studies were carr:ed out mostly on $\mathrm{C}_{7}-\mathrm{C}_{9}$ paraffins and performed under conditions where aromatics were the end products (reforming conditions). More directly related to the present studies are those on the hydrogenolysis of methylcyclopentanes and substituted cyclobutanes $(9,10)$. These studies have shown that isomerization of $\mathrm{C}_{6}$ paraffins and hydrogenolysis of cycloalkanes have common cyclic intermediates. This conclusion is clearly supported by the present work. In fact, comparison of the kinetic sequence obtained in the present studies which were concerned exclusively with hydrogenolysis 
shows that it is practically similar to that obtained in studies on the isomerization of HA (16). The results of the present investigation suggests that the hydrogenolysis reaction follows a substantially different path in the presence of high acidity at the catalyst sites. Acidity induces relatively high fragmentation with ease of molecular rearrangement by alkyl shift. The reaction kinetics become less dependent upon the details of the molecular structure of the $\mathrm{C}_{6}$ paraffin. As the catalyst acidity is lowered, more selective reaction mechanisms set in, becoming influenced by the molecular structure of the $\mathrm{C}_{6}$ paraffin.

The present research has shown that in the absence of gas-phase hydrogen, all of the possible rearrangements of the hexane chain may be observed. Their rates are different, reflecting more directly fine details of molecular structure and catalyst surface. With gas-phase hydrogen, more drastic consequences are obtained. At moderate pressures, low temperature, and high acidity, isomerization conditions are set up, and CHA is isomerized to methylcyclopentane with end formation of MPA to the exclusion of $\mathrm{HA}$. This indicates the advantages of rate studies on reaction (1) over those on net isomerization, hydrogenolysis, and dehydrocyclization for fundamental information on the elementary steps of hydrogen transfer and rearrangement of the hydrocarbon skeleton. As noted earlier, the present study differs from previous invectigations in this field not only for the absence of hydrogen in the gas phase, but also because isomerization equilibria for alkanes and cycloalkanes were not established in the gas phase. Experimental conditions were purposely chosen to this end. Successful fulfillment of this condition has permitted a more fine and direct observation of some of the effects of catalyst and molecular structure upon the individual reaction steps. This possibility may open the way to the application of reaction (1) to a systematic investigation of several parameters of the catalyst reaction system in alkane dyhydrocyclization. The combination of reaction (1) with the lyddrogen transfer reaction be- tween CHA and benzene, as investigated previously (1), offers the opportunity to follow the detailed steps involved in the aromatization of $\mathrm{C}_{6}$ paraffins. For mechanistic studies, this combination provides definite advantages over studies of overall aromatization of hexanes (17). Reaction (1), reflecting as it does in its kinetic development, some characteristics of net hydrogenolysis and isomerizations, may provide fruitful insight for catalyst and process development. A concrete suggestion, resulting from this research, is the possibility of introducing superior hydrogenolysis and dehydrocyclization activity in chromia by the addition of Re.

\section{ACKNOWLEDGMENTS}

We wish to express our appreciation to Prof. M. Boudart for a sample of P'-C, to Prof. R. I. Burwell, Jr., for a sample of chromia xerogel, to Dr. F. G. Ciapetta for a sample of $\mathrm{Cr}_{2} \mathrm{O}_{3}-\mathrm{Al}_{2} \mathrm{O}_{3}$, and to Dr. V. Haensel for a sample of acidified and nonacidified $\mathrm{Pt}-\mathrm{Al}_{2} \mathrm{O}_{3}$, Grateful acknowledgment is also made to the donors of the Petroleum Research Fund, administered by the Amorican Chemical Society, for financial support of this research

\section{REFERENCES}

1. Parhataxo, G.. J. Catal. 11, 269 (1968); 16, 1 (1970).

9. Sinfelt, J. H., Calal. Rev. 3, 175 (1970).

3. Pass, G., Littlewood, A. B., and Burwell, R. I., Jie, J. Amer. Chem. Soc. 82, 6281 (1966).

4. Soutes, R.. and Parravano, G.. J. Calal. 2, 324 (1963).

6. Mongan, A. E., and Somonjai, G. A., Surface Sci. 12, 405 (1968).

6. Estrup, P. J., private communication.

7. Newns, D. M., Phys. Rev. 178, 1123 (1969).

8. Giordano, N., and Moretti, E.. J. Catal. 18, 228 (1970).

9. Barron, Y., Maire, G.. Muller, J. M., and Gallt, F. G., J. Catal. 5, 428 (1966).

10. Matre, G., Ploudy, G.. Prudhomme, J. C., and Gault, F. G.. J. Catal. 4, 556 (1965).

11. Lkster, G. R., Paper Presented at the First North American Meeting of the Catalysis Society, 1969.

12. Davis, B. H., and Venuto. P. B., J. Calal. 15, $363(1969)$. 
19. Burwell, R. L., JR., Haller, G. L., Taylor, $K$. C., And Ruad, J. F., Advan. Calal. Relul. Subj. 20, 2 (1969).

14. Clark, A., Ind, Eng. Chem. 45, 1476 (1953). 15. Evering, B. L., and Waugh, R. C., Ind. Eng. Chem. 43, 1820 (1951); Ciapetta, F. G., and Hunter, J. B., Ind. Eng. Chem. 43, 147
(1953); Cull, N. L., and Brenner, J. H., Ind. Eng. Chem. 53, 833 (1961).

16. Voorhies, A., and Beecher, R. G., Preprint 20B, 61st Annual Meeting AIChE, Los Angeles, 1968.

17. Kogan, S. B., Bursian, H. R., and Davydova, Z. A.. Kinet. Catal. (USSR) 10, 1137 (1969). 